\title{
Impactos socioculturais no processo de turistificação da Vila de Encantadas, Ilha do Mel, Paraná, Brasil
}

\author{
Social and Cultural impacts in the tourism implantation process in Vila de \\ Encantadas, Ilha do Mel, Paraná, Brazil
}

\author{
Daniel Hauer Queiroz Telles (TELLES, D. H. Q.) \\ José Manoel Gonçalves Gândara (GÂNDARA, J. M. G.) ${ }^{* *}$
}

\begin{abstract}
RESUMO - Os impactos socioculturais partem da transformação ocorrida na comunidade da Vila de Encantadas, Ilha do Mel (Paraná, Brasil). Trata-se de um destino consolidado no litoral sul brasileiro que recebe visitantes de diversas regiões do Brasil e exterior, atraídos pela ausência de carros, estruturas rústicas de receptivo (pequenas pousadas e trilhas sem pavimento) e belezas em seus 95\% de área protegida. Nas décadas de 1980 e 1990, esse processo de turistificação resultou em uma nova realidade social. O objetivo da pesquisa é analisar os impactos, bem como compreender o surgimento de novas práticas. Uma pesquisa qualitativa foi realizada, com entrevistas semiestruturadas aos representantes comunitários do Conselho Gestor. É evidente que sem o enfrentamento de obstáculos focados na distribuição dos benefícios advindos do turismo se torna difícil evitar a crescente segregação.
\end{abstract}

Palavras-Chave: Impactos socioculturais; Turistificação; Comunidade local; Gestão; Ilha do Mel.

\begin{abstract}
The socio-cultural impacts are based on the transformation which occurred in Vila de Encantadas community, Ilha do Mel (Paraná, Brazil). This place is a consolidated tourist destination on the southern coast of Brazil, which receives visitors from several regions of Brazil and abroad, attracted by the absence of cars, rustic touristic support structures (small inns and unpaved trails) and beauties in its $95 \%$ natural protected areas. Throughout the 1980s and 1990 s, this touristification process resulted in a new social reality. The aim of the research is to analyze the impacts, as well as understanding the emergence of new practices. A qualitative research was accomplished using semi-structured interviews with the Island Council's members. Clearly, without facing obstacles focused on sharing the benefits become from the tourism it will be difficult to avoid the increasingly segregation.
\end{abstract}

Key words: Socio-cultural impacts; Touristification Process; Local Community; Management; Ilha do Mel - Brazil.

\footnotetext{
* Bacharelado e Mestrado em Geografia pela Universidade Federal do Paraná (UFPR). Doutorando em Geografia Humana pela Universidade de São Paulo (USP). Professor assistente no Curso Superior de Tecnologia em Gestão de Turismo da Universidade Federal do Pampa (UNIPAMPA). Endereço para correspondência: BR-116, 2141. CEP: 96300-000. Jaguarão, RS (Brasil). Telefone 53 3261-4269. E-mail: danieltelles@unipampa.edu.br

** Graduação em Turismo (Bacharelado) pela Universidade Federal do Paraná (UFPR). Especializações em Marketing Internacional pela SIOI de Roma e em Economia do Turismo pela Universidade Bocconi de Milão. Mestrado em Gestão de Empresas Turísticas pela SSCTS de Milão. Doutorado em Turismo e Desenvolvimento Sustentavel pela Universidade de Las Palmas de Gran Canaria. Pós-doutorados em Planejamento e Gestão de Hotéis e Destinos Turísticos pela Universidades de Alicante, Las Palmas, Málaga, Valencia e Vigo. Professor e Pesquisador do Departamento de Turismo e do Mestrado e Doutorado em Geografia (UFPR). Endereço: Rua Doutor Faivre, 405. Terceiro andar. CEP: 80.060-140 Curitiba - Paraná (Brasil). Telefone: 41 3360-5109. E-mail: jmggandara@yahoo.com.br
} 


\section{INTRODUÇÃO}

A Vila de Encantadas representa a realidade de muitos destinos turísticos insulares litorâneos brasileiros. No caso da Ilha do Mel, pode-se afirmar que o local representa um território em que o turismo já amadureceu e deixa suas consequiências, ao mesmo tempo em que se renova em perspectivas de melhorias das condições de vida dos habitantes locais e incremento econômico. Nesta vila de menos de mil habitantes permanentes, é possível ainda, identificar características culturais típicas do lugar e da região em que está inserida.

O fato de reconhecer tais aspectos permite trazer, através do presente artigo, os resultados obtidos em pesquisa efetuada no local no ano de 2007, as principais características culturais ao longo deste processo. Tais informações levaram em consideração a opinião da população habitante no local, tendo como objetivo a constatação da própria comunidade no que diz respeito às mudanças, aos impactos e às adaptações culturais frente à turistificação.

O recorte temporal do presente estudo culminou num período em que o turismo alcançava um momento crucial para a Ilha do Mel: crise de paradigma. Algumas modificações já passavam a ocorrer (capacidade de carga), entretanto no aspecto cultural ainda era perceptível a ascensão da crise para os diversos grupos sociais para então ocorrer uma futura resposta aos desafios no ciclo do turismo.

De que maneira o turismo interferiu em algumas das principais atividades e práticas socioculturais no local? Quais os indicadores sociais dessas mudanças, e que manifestações permaneciam acontecendo na cultura local? O processo de turistificação bem sintetiza a modernização da vida social em lugares como a Vila de Encantadas. Apesar de não ser o único vetor de influência de novos hábitos, práticas e valores, o turismo se destaca ao protagonizar a maior parte dos investimentos no local que, ao receber normatizações voltadas aos visitantes, se consolida como principal atividade socioeconômica, interferindo na cultura local.

O objetivo deste artigo é discutir sobre o processo de transformação de aspectos culturais num território bem específico que sofreu, desde o final da década de 1980 até janeiro de 2007, os impactos da turistificação. Identificar e analisar tais características 
permite que se tenha uma melhor compreensão do turismo em lugares que, até poucas décadas, eram habitados predominantemente por comunidades tradicionais.

Inicialmente, este estudo faz uma rápida síntese de conceitos que permitem sustentar as variáveis gerais propostas, a saber: território, aspectos socioculturais e turismo. Partindo de uma breve noção sobre a relação espaço e turismo, para se ter uma contextualização do território ao qual aquela sociedade se estabeleceu, foram apontados pontos importantes que auxiliam a compreensão das transformações técnicas no âmbito da cultura local. Complementando a sustentação teórica, são apresentadas definições propícias para os conceitos de patrimônio e cultura.

Na segunda parte está a caracterização da Ilha do Mel, com ênfase nos aspectos socioculturais da Vila de Encantadas. Esta vila se caracteriza por concentrar o maior número de habitantes oriundos do local, os nativos. Também apresenta características e problemas de cunho social mais acentuado, uma vez que os estágios de desenvolvimento inicial e médio do turismo, que aqui está denominado de turistificação, não expulsou os habitantes, como ocorreu mais significativamente em outros setores. Assim tem-se na Vila de Encantadas o convívio mais intenso entre o turismo e a comunidade local.

Para a caracterização foram utilizadas fontes primárias e secundárias de informações, ou seja, foram geradas ao longo da pesquisa algumas complementações necessárias para a análise do local. Foi separado em quatro temas principais, tendo sido imprescindível abstrair aspectos históricos e geográficos para a compreensão dos modos de vida locais: localização, aspectos políticos e de ocupação, aspectos históricos e sociais, aspectos econômicos.

A seguir está descrita a metodologia deste estudo, salientando a geração das informações para a investigação dos aspectos socioculturais da Ilha do Mel, com ênfase na Vila de Encantadas. Tendo prevalecido uma abordagem qualitativa, justifica-se esta opção e fica apresentado de que forma foi efetuada a geração e análise das informações com a sociedade. A metodologia pode ser resumida em uma abordagem sobre os aspectos culturais a partir da visão da própria população local.

Finalmente, o artigo expõe os resultados do estudo destacando os assuntos que mais importam para o conhecimento público e científico. O turismo em pequenas ilhas, a partir desta contribuição necessita ser debatido de maneira específica pelos órgãos 
planejadores e de gestão territorial, por abrigarem características socioculturais distintas das continentais. Tal constatação reforça a elaboração de estratégias ao planejamento turístico em um contexto internacional, visto que no litoral brasileiro, não raro, o processo de turistificação é bastante nocivo aos bens culturais e à originalidade dos modos de vida das populações insulares.

\section{LUGAR, ASPECTOS SOCIOCULTURAIS E TURISTIFICAÇÃO}

O enfoque teórico para a apresentação do artigo se baseia em uma linha argumentativa que parte do conceito de espaço e território passando, também, por uma abordagem teórica da sociologia. Ambas as colocações se voltam para o turismo. Encerra-se com discussões acerca das questões culturais e identitárias de lugares aonde o turismo se desenvolve, trazendo ainda uma contribuição sobre a questão relacional entre os diferentes elementos que constituem esse lugar, através do conceito de patrimônio ambiental, adaptado a destinos como a Ilha do Mel.

O espaço passou a ser palco de transformações sociais. Estas transformações, com o transcorrer da história das sociedades, permanecem em constante evolução e configuram modificações na natureza. A perspectiva espacial enquanto instância da sociedade considera que este "contém e é contido pelas demais instâncias" como a "economia, o político-institucional e o cultural-ideológico". Desta maneira "a essência do espaço é social" (SANTOS, 1992, p. 2).

A ideia de movimento aproxima as categorias de espaço e de tempo ao turismo, conotando a noção de turistificação. Dentro desta dupla interferência, busca-se em conceitos de cada vertente, atribuir a noção de desenvolvimento turístico sem, no entanto, incorrer aos contrapontos intrínsecos ao próprio conceito de desenvolvimento (CARDOSO e FALETTO, 1981; FURTADO, 1992; SOUZA, 1995).

Nas considerações de Vera et alii. (1997) ao relacionar espaço e turismo, caracteriza aquele como sendo suporte e fator por sua condição geográfica. Completa considerando que tal condição varia de acordo com atributos de caráter qualitativo de valor intrínseco - naturais ou culturais. Ao descrever a variação qualitativa, afirma que esta "pode derivar da valoração social a que o espaço é conduzido" (p. 61) o que 
significa afirmar que existe um processo de "adequação dos recursos ou atrativos, e assim a sua conversão em produto e oferta, objeto de venda e consumo turísticos" (VERA et alii. 1997, p. 61).

O turismo possui diferentes maneiras de abordagem. É, de acordo com Rodrigues (1995, p. 17), "fenômeno econômico, político, social e cultural dos mais expressivos das sociedades ditas pós-industriais". De acordo com a amplitude, nas palavras de Ruschmann (1997, p. 59) "constitui um conjunto de equipamentos muito diversificados de empresas e práticas cujos impactos sobre o meio ambiente diferem quantitativa e qualitativamente entre si e, por isso, necessitam ser avaliados isoladamente".

R. Knafou (1999, p. 72-73), em seu artigo "Turismo e Território: Por uma abordagem cientifica do Turismo" caracteriza três formas de relação entre estes dois aspectos. A primeira diz respeito aos territórios sem turismo, que constituem locais e/ou regiões aonde não ocorre o turismo. De acordo com o autor, "há cada vez menos territórios sem turismo" devido a fatores como o progresso dos transportes e acessibilidade a áreas remotas. A segunda forma é relativa ao turismo sem território. Constitui sítios ou lugares criados e/ou equipados, sem existir vínculos culturais com a região acolhedora, se denominam de "espaços receptáculos", conforme o autor. A terceira forma refere-se aos "territórios turísticos", locais onde ocorre a relação entre turistas e sociedade acolhedora. Devido a isso o autor caracteriza estes, constituídos por "problemas delicados de planejamento". Podem ser relacionadas a estes territórios turísticos, as comunidades autócnes.

A conjuntura atingida pelo período técnico-científico-informacional torna as localidades de difícil abstração. Uma vez que é a extensão dos diversos sistemas que mune o lugar de singularidades (YÁZIGI, 2001), não necessariamente tornando-os sujeitos, a distinção entre local e lugar instiga a elaborar uma síntese, mesmo que prévia, sobre o lugar como expressão da turistificação.

Existem diferentes formas não-convencionais de turismo também considerados alternativos. O turismo ecológico, de aventura, rural, gastronômico são apenas alguns exemplos destas manifestações de modalidades. As características destes tipos de turismo variam de acordo com a demanda turística, com os "tipos de turista" (KRIPPENDORF, 2000). Estas novas manifestações da atividade surgiram a partir da 
"crise do modelo de turismo convencional que se enquadra numa grande transformação social, que assume como traços distintivos o resgate do individual e autêntico incluindo a volta à natureza nessa busca de autenticidade" (DIAS, 2003, p. 17).

Constantemente a ideia de patrimônio é entendida a partir de sua classificação quanto natural, histórico e cultural. Muitas vezes essa classificação é dúbia. Pode ocorrer dessa maneira reducionismo de alguns níveis abordados como acontece com a utilização dos termos cultura, turismo e ambiente, de acordo com E. Yázigi (2003, p. 155), ficando em "gavetas separadas no resto da organização social e econômica" ficando comumente nos planos de governo "como que pairando no ar", "o que reduz a dimensão de seus conteúdos" empobrecendo a "possibilidade de planejamento" ( $p$. $155)$.

Para Azevedo (1998, p. 149) patrimônio, cultura e turismo são variáveis nitidamente interativas, sendo a cultura "geradora de patrimônio(s), a força maior que envolve o pensar o sentir o fazer o viver representa a feição singular de um povo". O patrimônio por sua vez sendo o "conjunto de bens herdados, construídos e em construção mescla passado, presente e futuro" (p. 149).

Para este artigo, compreende-se que as manifestações culturais de determinada comunidade, no caso da Vila de Encantadas e Ilha do Mel, decorrem das atividades banais existentes. Das atividades do cotidiano, que mesmo pouco promovidas enquanto patrimônio ou símbolo de visibilidade a ser exportado constitui na ocasional coesão que ocorre em alguns territórios. Por isso, a necessidade de se recorrer à sazonalidade enquanto conceito que considera o movimento temporal na manifestação de tais práticas, onde estão incluídas: a pesca, o futebol de areia, as reuniões associativas ou não, entre outras. Por isso a importância da concepção miltoniana de buscar compreender o mundo a partir do lugar (SANTOS, 2008).

Essa idéia de processo permite associar ao significado de Patrimônio Ambiental (YÁZIGI, 2006). Este, para o autor, relaciona características de ser e devir dos aspectos relacionais existentes em determinado recorte geográfico de análise. A consideração se baseia ainda em algumas questões que se atrelam à idéia de lugar e cotidiano (YÁZIGI, 2001). Para Menezes, “o patrimônio é vivo” (MENEZES, 2004, p. 24).

Ainda em relação ao ponto de vista do processo, verifica-se a pertinência do uso da idéia de lugar como importante elemento abstrato a ser investigado. A contribuição 
maior sobre esta idéia considera tão somente pela conjuntura de seu significado. Somente possível de ser entendido "considerando a extensão de seus sistemas esse - o lugar - tem uma personalidade sim, mas não é o sujeito" (YÁZIGI, 2001, p. 38). Atributos que se somam e que, ainda, devido à efemeridade dos aspectos que o constituem é, geralmente, suscetível às "forças aplainadoras da globalização" (idem, p. 41).

Alguns pensadores, como A. Touraine (2002), definem a sociedade que se pauta no determinismo econômico, aquela cada vez mais marcante na sociedade pós-moderna. Tal como a proposta temática do projeto, apoiada na idéia de que "formas de vida coletiva sejam manifestações de uma capacidade e de uma vontade de autotransformação da sociedade" (TOURAINE, 2002, p. 70). Assim sendo, dos traços socioculturais relacionados à maneira de como os lugares reagem face à turistificação.

A utilização consumista de formas de patrimônio tem no turismo, uma constante. Desde as condicionantes naturais, paisagísticas e também históricas, artificiais ou pitorescas, entre outras, o patrimônio que se constrói a partir da cultura e do cotidiano de determinados lugares, pode conservar ou transformar as construções - materiais e imateriais - e até mesmo destruí-lo (MENEZES, 2004). O patrimônio, portanto, ao ser apropriado como produto turístico, tem provocado problemas sérios, nas palavras do autor, se referindo a alguns lugares turistificados:

\footnotetext{
A transformação em produtos de consumo massificado tem provocado problemas sérios na apreensão, interpretação e comunicação de seu patrimônio histórico, além da exclusão social de parcela de sua população. $\mathrm{O}$ planejamento turístico ainda não atendeu a questões infra-estruturais que podem preservar a cidade e incluir a população no usufruto do bem patrimonial que elas são e no bem de consumo em que elas se transformaram (MENEZES, 2004, p. 27).
}

Diante dessas considerações iniciais acerca dos conceitos, fica entendida a importância do contexto histórico para o entendimento e para o planejamento de uma determinada sociedade e seu território. Entender que "tudo é história" é fundamental, considerando que "somente o desenvolvimento histórico permite sopesar e avaliar em suas relações respectivas, os elementos do presente" (STRAUSS, 1996, p. 26).

Em síntese, as concepções de território, de ambiência relacional, de patrimônio e de lugar, dentro da assumida consideração pelo processo histórico do presente, podem 
ser conjugadas no que se entende por turistificação. Longe de encerrar esta discussão, apresenta-se uma das maneiras de abordagem e a ser revista por outras perspectivas.

\section{A EVOLUÇÃO DO TURISMO NA VILA DE ENCANTADAS}

As informações necessárias para analisar a área de estudo foram encontradas em documentos e bibliografia específica existente nos arquivos do órgão público competente, a saber o Instituto Ambiental do Paraná (IAP), além de estudos publicados. Entretanto, tais fontes não foram suficientes para descrever os aspectos sociais e culturais, que estão fortemente relacionados aos aspectos geográficos e históricos. Dessa forma, foram geradas informações complementares ao objetivo específico deste artigo para caracterizar a área de estudo.

As informações que constam neste tópico estão organizadas da seguinte forma: inicialmente estão descritas as informações referentes à Ilha do Mel, para então especificar, por temas, a Vila de Encantadas.

\subsection{LOCALIZAÇÃO}

A Ilha do Mel está situada na desembocadura do complexo estuarino da Baía de Paranaguá. (Figuras 1, 2). É um local representado por riquezas naturais e culturais. Gerações de visitantes vêm conhecendo-a, freqüentando-a e acompanhando suas mudanças. De sua área, grande parte é protegida e preservada. Possui alguns setores de ocupação humana, tradicionalmente ocupados por pescadores e antigos habitantes e mais recentemente por pessoas de fora.

A Vila de Encantadas está situada no Sul da Ilha do Mel (Figura 3) e situa-se ao longo de quase toda a linha de praia voltada para o continente, denominada Prainha pelos habitantes. À Oeste está o limite com o canal de acesso à navegação ao porto de Paranaguá. Ao Norte, acompanha a base do morro do Miguel, ou Bento Alves, o maior e mais elevado de toda a Ilha. Ao Sul, situam-se os morros do Caraguatá e o Morro do Encantado como limites. À Leste, em direção ao Oceano Atlântico, limita-se com o 
Parque Estadual da Ilha do Mel, onde estão situados morros, praias e a gruta (Fotos 1 e 2) (TELLES, 2007).

\subsection{ASPECTOS POLÍTICOS E DE OCUPAÇÃO}

A Ilha do Mel é pertencente ao município de Paranaguá. É tombada pelo Patrimônio Histórico, Artístico e Natural do Estado do Paraná (PARANÁ, 1953). Está vinculada aos poderes de gerenciamento do governo estadual desde 1982 quando da concessão de uso sob forma de aforamento (PARANÁ, 1982). Esta transferência passou do S.P.U. (Serviço do Patrimônio da União), vinculada ao Ministério da Fazenda, para o governo do Paraná a responsabilidade, que por sua vez direcionou aos poderes do ITCF (Instituto de Terras e Cartografia) autorização para outorgar concessões de uso na Ilha através do Decreto Estadual No. 4.964/1985 (PARANÁ, 1986). Com a extinção do ITCF e implantação do Instituto Ambiental do Paraná (IAP), passou-se para a responsabilidade de gestão a este órgão, os poderes para a fiel execução da gestão no local (PARANÁ, 1986; PARANÁ, 1996).

FIGURAS I e II - LOCALIZAÇÃO CARTOGRÁFICA DA ILHA DO MEL, ESTADO DO PARANÁ BRASIL

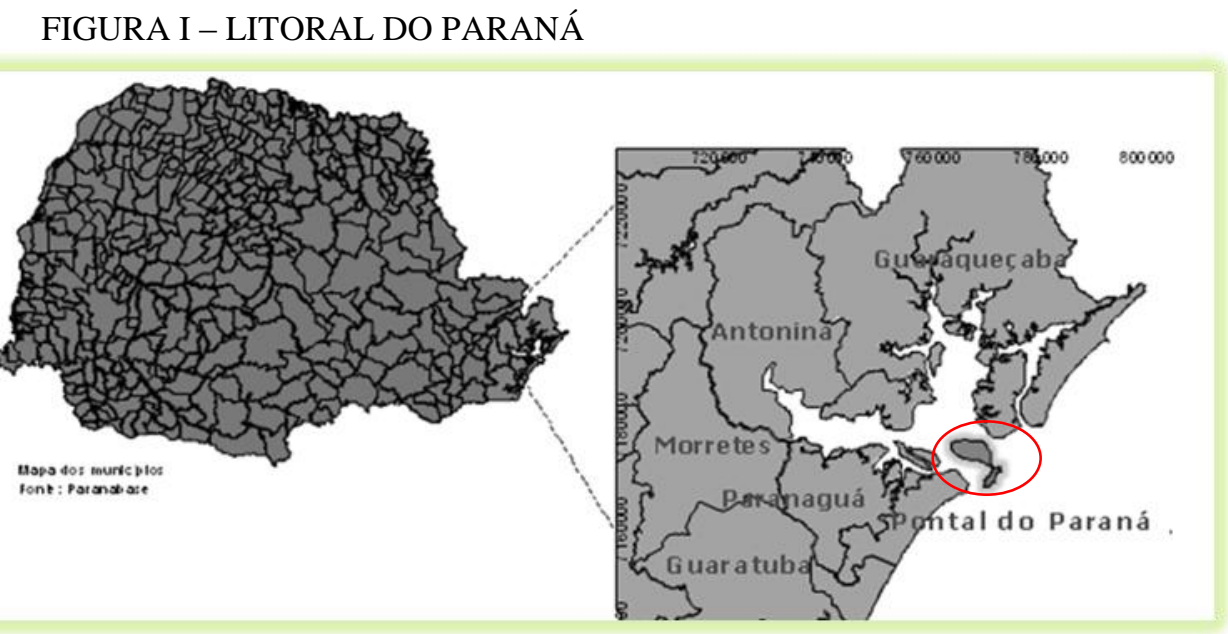

FIGURA II - VILA DE ENCANTADAS - ILHA DO MEL

FONTE: TELLES (2007, p. 45). 


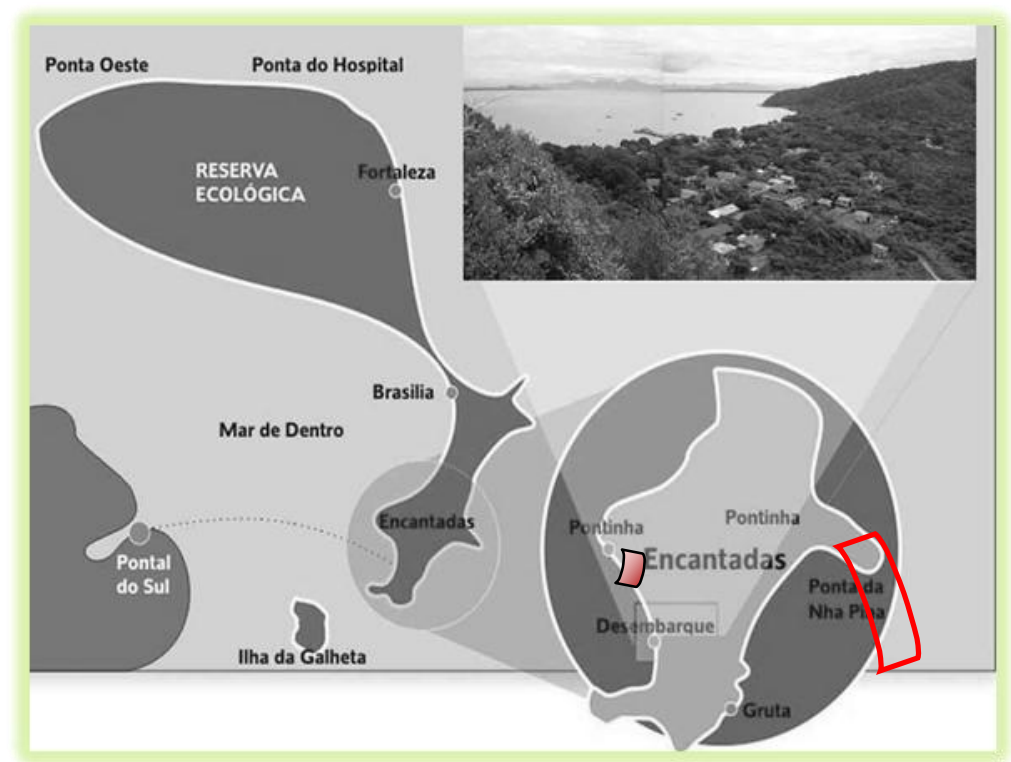

ORGANIZADO PELOS AUTORES - 2011

FONTE: QUEIROZ-TELLES; GONÇALVES-GÂNDARA (2011, p. 190).

A ocupação da Ilha do Mel consiste basicamente em áreas de Unidade de Conservação e Setores de Ocupação, possui uma área de aproximadamente 2.762 hectares e perímetro de aproximadamente 35 quilômetros (PARANÁ, 1996). São atualmente reconhecidas oficialmente, duas áreas de Unidade de Conservação e quatro setores de ocupação. As unidades de conservação são: a Estação Ecológica da Ilha do Mel (EEIM) e o Parque Estadual da Ilha do Mel (PEIM). Os Setores de Ocupação são: Fortaleza, Nova Brasília, Farol, e Vila de Encantadas. Os setores de ocupação da Ponta Oeste e da Praia Grande não são reconhecidos oficialmente pelo Estado (PARANÁ, 2006).

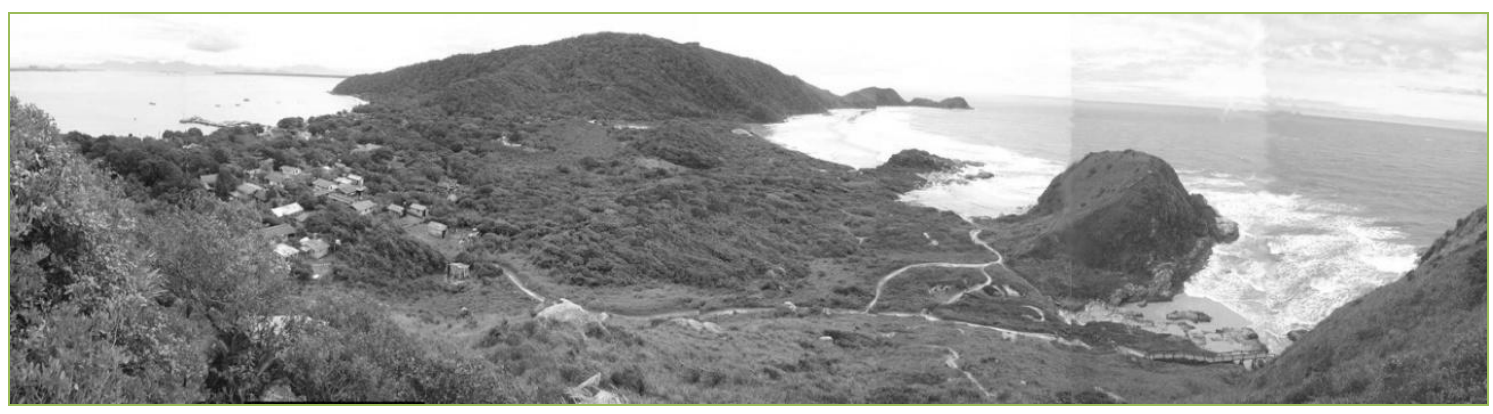

FOTO 1: A VILA DE ENCANTADAS, O PARQUE ESTADUAL DA ILHA DO MEL E AS PRAIAS DO MAR DE FORA FOTO: DANIEL H. Q. TELLES (2006). 
Todas as áreas de ocupação dentro da Ilha do Mel estão em zona de amortecimento das Unidades de Conservação ${ }^{1}$. Estão, portanto, condicionadas aos termos existentes na Lei 9.985, de 18 de Julho de 2000 que regulamenta o Sistema Nacional de Unidades de Conservação - SNUC (BRASIL, 2000).

De acordo com documento Diagnóstico para Comissão de Elaboração do Plano de Instruções Básicas para a Ilha do Mel, (PARANÁ, 1999), a Vila de Encantadas é um dos quatro povoados oficialmente existentes na Ilha do Mel, de acordo com a classificação do Estado atual sobre as áreas de ocupação ${ }^{2}$.

\title{
3.3 ASPECTOS HISTÓRICOS E SOCIAIS
}

O quadro demográfico que compõe atualmente a Ilha do Mel compreende-se pela interação entre três componentes predominantes, como explica o texto oficial:

\begin{abstract}
[...] apresenta dois grupos sociais distintos e bem definidos de moradores fixos: nativos e pessoas de fora. Os nativos são pessoas nascidas na ilha ou nas imediações, geralmente conservam o biótipo característico das populações litorâneas do Estado, além de ainda apresentarem laços culturais e relações de parentesco marcantes. O segundo grupo é denominado como os de fora, pessoas não nascidas na ilha que ali se estabeleceram, principalmente em busca de sossego e com a finalidade de trabalhar no comércio (bares, pousadas e restaurantes). Cita-se ainda um terceiro grupo social na ilha, representado pelos veranistas com casa na ilha, que freqüentam o local esporadicamente. PARANÁ (1996, p. 96).
\end{abstract}

Os habitantes tradicionais da região eram os índios Carijós, que habitaram o litoral sul brasileiro desde a Lagoa dos Patos até Cananéia (PARANÁ, 1996, p. 22). Os índios carijós habitavam a porção meridional do litoral brasileiro durante a chegada dos primeiros europeus (STADEN, 2009). Os sambaquis localizados no Sul da ilha, área correspondente à vila das Encantadas, datam da existência dos indígenas há cerca de 6.000 anos (FIGUEIREDO, 1954, p. 85).

\footnotetext{
${ }^{1}$ Área no entorno de uma unidade de conservação, onde as atividades humanas estão sujeitas a normas e restrições específicas, com o propósito de minimizar os impactos negativos sobre a Unidade.

${ }^{2}$ Os setores de ocupação da Ponta Oeste e da Praia Grande não são oficialmente reconhecidos. Estes focos de ocupação estão dentro de áreas de preservação ambiental e devem ser oficializados após a realização da Regularização Fundiária (SOARES, 2006).
} 


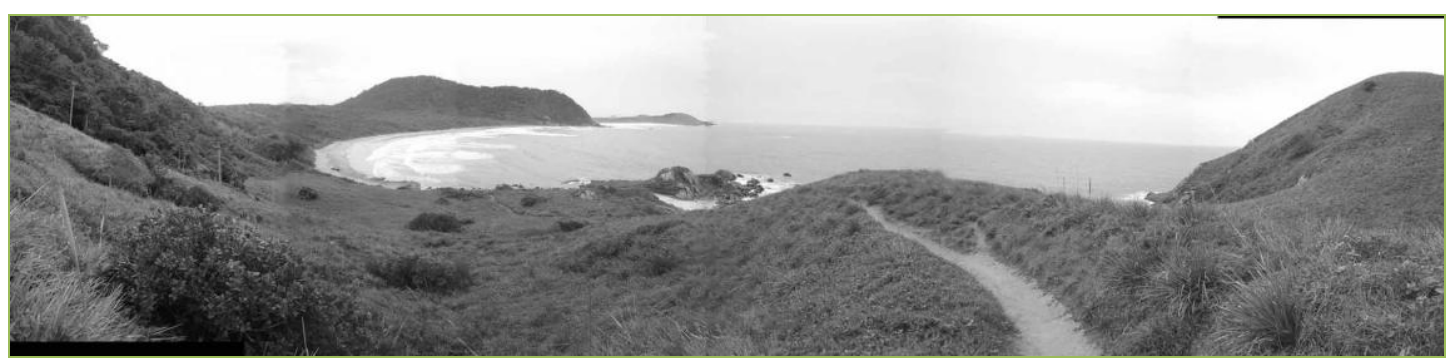

FOTO 2 - PRAIA DO MIGUEL E TRILHA DO MORRO DO SABÃO. PARQUE ESTADUAL DA ILHA DO MEL

FOTO: DANIEL H. Q. TELLES (2006).

A miscigenação de raças, entre os índios e os europeus, ocorreu quando da ocupação portuguesa na região litorânea do Paraná. O motivo dessa ocupação seria a procura por metais preciosos e a escravização de indígenas (MARTINS, 1995). Existem ainda, nos relatos arquivados nas coletâneas sobre a Ilha do Mel, em PARANÁ (1996, p. 23) hipóteses de que mesmo antes dos portugueses, haviam passado pela região embarcações de diversas origens européias, francesas, castelhanas e portuguesas, que buscavam descanso e refresco no caminho das Índias. Esta resultante cultural culminou no tipo mameluco, que retrata a característica racial da maioria dos habitantes nativos da Ilha do Mel, mistura de índios carijós e brancos, principalmente portugueses. A inserção dos habitantes externos marcou uma mudança na composição étnica, social e cultural da ilha (Foto 3).

A área das Encantadas e adjacências possui particularmente um rico passado histórico, tendo sido freqüentada por indígenas, piratas, missões jesuíticas e escravos. Em meados do século XX passou a consolidar-se como a vila dos pescadores. O aspecto geográfico, formando um grande arco voltado para o continente provavelmente proporcionou esta preferência por diversos ocupantes e freqüentadores ao longo da história (ESTEVES, 2004, p. 83).

A Vila de Encantadas é composta por habitantes tradicionais, os nativos e filhos de nativos, e de pessoas de fora (comerciantes, empresários e moradores de segunda residência) que passam períodos na ilha, chamados veranistas ou população flutuante. A composição da sociedade local é genericamente classificada em "moradores" e "comerciantes", ou também "nativos e de fora". Os segundos grupos são os imigrantes sazonais ou perenes habitantes que estão no local há algum tempo, fazendo parte do contexto social, entretanto que não têm ligação familiar com os habitantes tradicionais. 


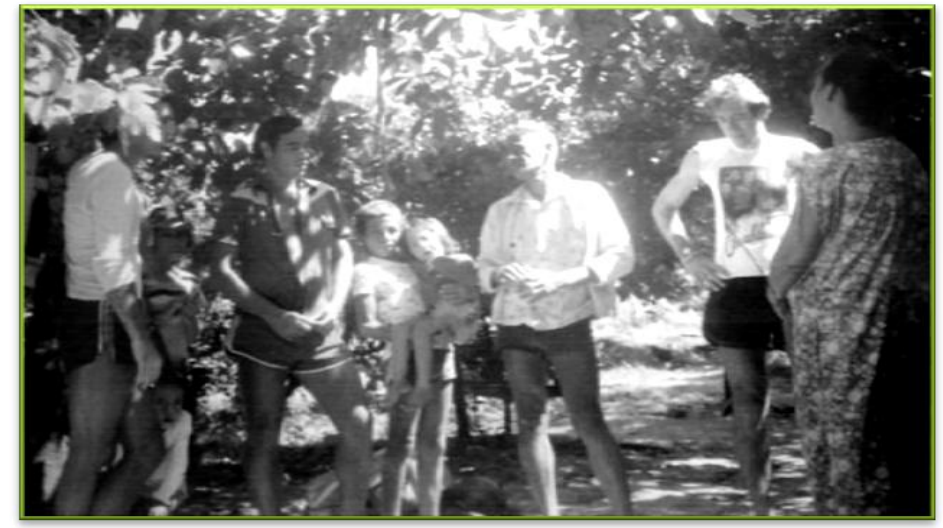

FOTO 3 - ESTABELECIMENTO DE CONTATOS ENTRE VISITANTES E NATIVOS, DÉCADA DE 1970. FOTO: PAULO J. SOAVINSKY (MEADOS DA DÉCADA DE 1970).

Segundo informações secundárias e primárias, a configuração fundiária inicial da vila estava sob o domínio de três famílias que detinham grande parte das terras para o uso agrícola entre outras atividades. A partir dessa condição, prevaleceu a premissa do direito a terra para os nativos. Dessa maneira, a área de ocupação humana da Vila de Encantadas expandiu-se de acordo com a quantidade de habitantes locais que passaria a compor o quadro demográfico da vila.

A inserção dos moradores provenientes de outras regiões na Vila de Encantadas marcou uma mudança na composição étnica, social e cultural da vila. O desnível educacional e de poder aquisitivo muitas vezes acarretou em conflitos advindos principalmente da concorrência pelas atividades comerciais de exploração do turismo (KRAEMER, 1978; PARANÁ, 1996).

Algumas destas transformações no âmbito social foram consideradas como sérios problemas no local. Até alguns anos atrás, a predominância de turistas de perfil e expectativas diferentes dos atuais, relacionadas à imagem da Ilha do Mel, marcaram o local por "transformações nos modos de vida da população local como o abandono de atividades tradicionais, mudança de comportamento dos jovens, consumo de drogas e alcoolismo" (SILVEIRA, 1998, p. 144).

As associações são entidades que representam alguns dos grupos sociais, em prol de objetivos, reivindicações, benefícios e responsabilidades (Fotos 4 e 5). Mediam a relação dos indivíduos e dos órgãos de governo, no intuito de promover o beneficio dos seus representados. Habitantes em geral unem-se para a formação das associações, geralmente com objetivos comuns, buscam fortalecerem-se no conjunto para obterem 
maior expressividade perante questões de interesse. As principais associações da Ilha do Mel possuem caráter deliberativo, com representação no Conselho Gestor da Ilha do Mel. Parte da população deve procurar a Associação dos Moradores de Encantadas, quando tem interesse em reivindicar e participar das ações comunitárias.

\section{METODOLOGIA}

Este estudo enfoca especificamente analisar os impactos socioculturais ligados ao processo de desenvolvimento do turismo na Ilha do Mel. Baseia-se em outras publicações antes apresentadas e elaboradas no intuito de aprofundar e divulgar o conhecimento sobre o local e a questão. (TELLES, 2007; TELLES e GANDARA, 2009, TELLES, et al. 2011).
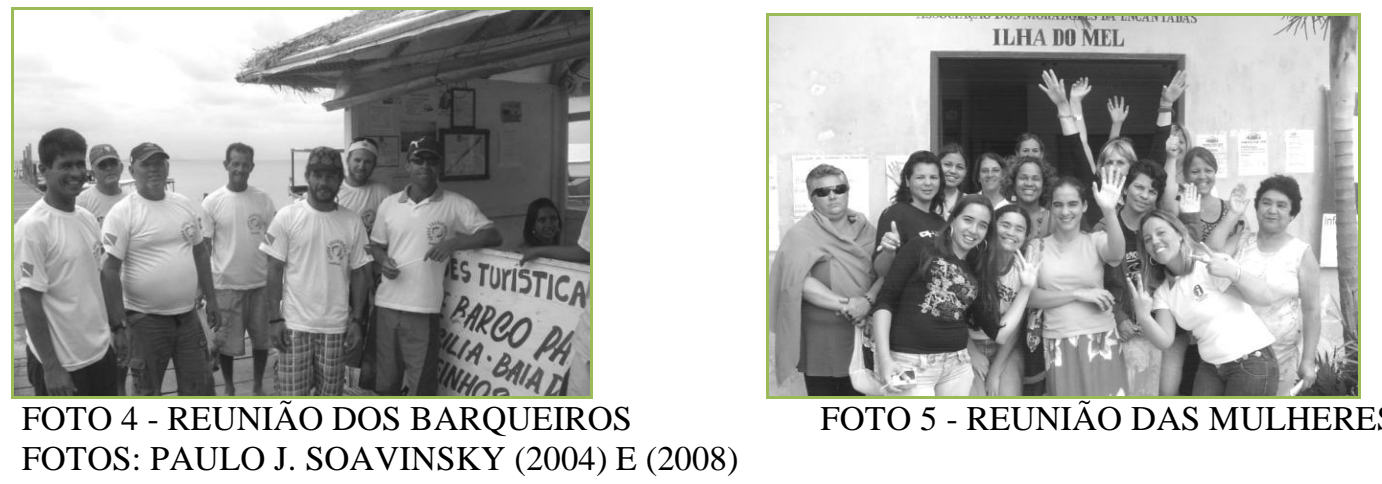

Como técnicas de pesquisa, foram realizadas pesquisas fotográficas e bibliográficas em trabalhos jornalísticos e acadêmicos sobre área e tema de estudo, documentos oficiais, a legislação incidente diretamente na Ilha, em especial a que normatiza o conselho Gestor da Ilha do Mel. Foram utilizados, ainda, os resultados obtidos em entrevistas semiestruturadas e direcionadas com gestores públicos e privados, representantes da sociedade civil sobre os diferentes grupos de interesse na gestão da Ilha do Mel.

O principal eixo metodológico desta investigação acompanhou a existência institucionalizada do Conselho Gestor da Ilha do Mel. Uma vez que criado, como interlocução entre os anseios sociais e dos órgãos oficiais competentes, esta organização 
se voltou ao objeto central deste artigo, oferecendo-lhe pontos a serem explorados de um ponto de vista analítico-crítico.

A abordagem com a componente social passou por duas etapas neste trabalho. Primeiramente foi realizada abordagem experimental, com aplicação de questionáriosteste; fase preparatória apontando o método a ser seguido. A seguir foram realizadas entrevistas com representatividades dos grupos sociais representados junto aos chamados sujeitos de interesse da pesquisa. Houve, também, entrevistas específicas para a obtenção de informações gerais, utilizadas na caracterização da área de estudo, entretanto os depoimentos realizados com representantes da sociedade nos grupos organizados sob a forma de associações ou ligados a cargos administrativos e de gestão no Conselho Gestor da Ilha do Mel, seguiram um roteiro semiestruturado de entrevista. A obtenção de informações primárias consistiu no período dos anos de 2006 e 2007.

De acordo com a Portaria de número 87 do Instituto Ambiental do Paraná, de 19 de Maio de 2005, em seu artigo $2^{\circ}$, o Conselho Gestor da Ilha do Mel é constituído da seguinte forma a partir da data de publicação (PARANÁ, 2005):

- Secretaria de Estado do Meio Ambiente - SEMA;

- Instituto Ambiental do Paraná - IAP;

- Sociedade dos Amigos da Ilha do Mel;

- Associação dos Moradores da Praia de Encantadas - AME;

- Prefeitura Municipal de Paranaguá;

- Paraná Turismo - PRTUR;

- Associação dos Barqueiros do Litoral do Paraná - ABALINE;

- Associação dos Comerciantes da Ilha do Mel - ACOIM (Brasília e Encantadas);

- Associação dos Nativos da Ilha do Mel - ANIMPO;

- Batalhão de Polícia Florestal - BPFLO;

- União das Mulheres da Ilha-EMILHA ${ }^{3}$.

Como finalidade deste Conselho, consiste a de representar as reivindicações da sociedade da Ilha do Mel junto ao poder público, em virtude de suas necessidades e realizações de planos de governo e projetos pelo bem comum da comunidade. Tem como intuito gerir em administração participativa, "tendo a responsabilidade de

\footnotetext{
${ }^{3}$ A presidência e secretaria executiva do Conselho Gestor são cargos determinados pelo Estado, sendo representantes do IAP e /ou SEMA.
} 
negociar interesses diversos, e por vezes conflitantes, e dirimir divergências, a fim de tomar decisões em consenso que garantam a proteção do ambiente natural e considere as necessidades sociais do local" (ALEGRIA e SILVA, 2006).

A sociedade local entendida como sistema social possibilitou serem consideradas as particularidades e dotada de relações internas específicas. Dentre os grupos que participam da organização social representados nas entrevistas, foram considerados os que possuíam uma compreensão diferenciada dos elementos que compõem a realidade, e legitimidade política em relação à sociedade, seja pelo poder público representado, seja pela sociedade civil organizada. Estes constituíram a fonte de informação para a análise dos temas, sendo devidamente caracterizados quanto à sua representatividade na sociedade local e/grupos de poder relacionados.

Os grupos sociais enfocados nesta pesquisa foram os atores sociais governamentais representados no Conselho Gestor. Alguns grupos não foram representados diretamente. Os pescadores, carreteiros entre outros não são representados separadamente junto a uma espécie de organização, portanto não existindo representatividade direta destes grupos. Estes atores sociais utilizam a Associação dos Moradores para suas questões políticas e interesses.

Grande parte dos entrevistados foi determinada a partir da composição do Conselho Gestor da Ilha do Mel, pelo fato desse Conselho atribuir aos membros componentes, representatividade politicamente relevante. Dentre os membros - titulares ou suplentes - foram entrevistados aqueles que tivessem ligação com a Vila de Encantadas, deste modo alguns dos integrantes não participaram das entrevistas por representar grupos sociais referentes a outras comunidades na Ilha do $\mathrm{Mel}^{4}$.

As entrevistas foram realizadas com base num roteiro e cada entrevistado fez as declarações de acordo com seu grau de conhecimento, posição político-ideológica e representatividade social. A aplicação das entrevistas consistiu em parte fundamental dentro das variáveis do trabalho, pois elas foram realizadas com o intuito de obterem indicadores sobre os temas trabalhados, foram metodologicamente estabelecidas a fim

\footnotetext{
${ }^{4}$ Constituem estes grupos sociais: ANIMPO - Associação dos Nativos da Ilha do Mel e Ponta Oeste. Esta Associação representa os nativos da Praia Grande, Vila do Farol, Nova Brasília, Fortaleza e Ponta Oeste. A AME - Associação dos Moradores de Encantadas possui esta representatividade na área de estudo. ACTURIM - Associação dos Comerciantes e do Turismo da Ilha do Mel. Esta Associação representa estes setores (comércio e turismo) na Vila do Farol e Nova Brasília. A Associação dos Comerciantes da Ilha do Mel, Encantadas representa esta representatividade na área de estudo.
} 
de levantar informações junto a representantes públicos. Foram exploradas questões gerais e específicas através de perguntas abertas,

As entrevistas foram realizadas entre os meses de setembro de 2006 a fevereiro de 2007. Foram feitas diretamente entre o pesquisador e o entrevistado. Algumas entrevistas foram gravadas na íntegra, outras acompanhadas de anotações. Tiveram duração de quarenta minutos até duas horas.

Ao longo do período da pesquisa foram realizadas diversas visitas a campo. Este período possibilitou o reconhecimento das manifestações aparentes das problemáticas desta unidade geográfica de análise. As informações secundárias foram obtidas junto a informações existentes nas instituições públicas e também em artigos, relatórios e estudos entre outros documentos específicos sobre a área de estudo.

Visando identificar as características essenciais, os significados, as convergências e divergências dos conteúdos das entrevistas, utilizou-se a análise dos conteúdos que "permite abordar atitudes, valores, representações, mentalidades e ideologias" (LAVILLE; DIONNE, 1999).

\section{RELAÇÃO ENTRE AS QUESTÕES SOCIOCULTURAIS E A EVOLUÇÃO DO TURISMO}

Com o passar das últimas décadas ficou marcando dentre a população local, divergências entre pontos de vista sobre diferentes aspectos. De acordo com a opinião de parte dos entrevistados, a influência dos forâneos ${ }^{5}$ descaracterizou a antiga relação de integração entre os habitantes tradicionais. Isto acarretou uma relação de desconfiança por parte dos nativos, consolidando o aspecto da segmentação da sociedade.

A política interna da Vila de Encantadas era organizada através da ação política de Associações, cuja principal é a Associação de Moradores das Encantadas (AME), que de acordo com seu estatuto representa a comunidade como um todo, frente às suas decisões e reivindicações. Existem outras associações como a dos comerciantes, das mulheres da ilha, entre outras, sendo estas as mais diretamente ligadas à comunidade.

\footnotetext{
${ }^{5}$ Forâneo: adj. (lat foraneu) Que é de terra estranha; estranho, forasteiro. (MICHAELIS, 1998, p. 977).
} 
As opiniões dos entrevistados se dividiram quanto ao funcionamento da política interna no local. Existia maior representatividade apontando para as críticas a este assunto. Predominavam os interesses individuais ou de alguns grupos isolados, resultante da atual segmentação da sociedade. Alguns grupos sociais não tinham interesse em participar das reuniões e de inserção política, representando uma baixa perspectiva com relação a mudanças. Essa constatação retratou a percepção dos habitantes em relação ao seu próprio contexto do desenvolvimento turístico.

A maneira como os antigos habitantes possuíam suas relações familiares e sociais, foram perdendo expressividade em razão da interferência dos novos habitantes. Um processo favorável economicamente para apenas alguns nativos que causou aquilo que uma minoria denominou como "excesso de fraternidade" para com os habitantes locais. Devido à premissa do "direito a terra" estes habitantes se submeteram a comercialização do espaço que possuíam quase que exclusivamente. Foi possível identificar a relação entre as causas de exclusão social e criação de conflitos com os processos de movimentação econômica e politização dos atores sociais na área de estudo.

A Integração Social aparece como um tema paradoxal. Se por um lado é negativamente acentuado, por outro, eram visíveis as manifestações culturais banais através de atividades coletivas (exemplos: pesca da tainha, futebol na areia). Tal aspecto assumiu diferentes formas desde a sazonalidade. Durante os meses de verão e férias existem divergências e competitividade em diversos níveis socioeconômicos, segregando pontos de vista e gerando conflitos e resultando em maiores dificuldades no sentido de um objetivo maior comum a todos. Os aspectos referentes aos benefícios e às responsabilidades dos diferentes grupos sociais na área de estudo puderam ser considerados indefinidos, ou inexistentes. Esta falta de clareza quanto à participação e a importância desta questão em todo o processo de desenvolvimento turístico puderam ser relacionadas às razões do estado de insatisfação e problemáticas por parte dos habitantes, comerciantes, barqueiros e habitantes em geral, que em sua grande maioria dependiam do turismo.

Os hábitos culturais da sociedade foram citados pelos depoimentos como sendo aqueles acontecimentos típicos que aconteciam na Vila de Encantadas. Existiam iniciativas que são reconhecidas e elogiadas pela maioria das opiniões sobre o assunto. 
Era o caso do grupo de teatro "Arteiros da Ilha", grupo de artistas que apresentam peças baseadas em roteiros criados pelos próprios habitantes e pelo grupo, em temas relacionados à Ilha do Mel e à comunidade de Encantadas. Sobre este aspecto há uma grande riqueza cultural em comunidades marítimas, em especial nas sociedades habitantes em ilhas oceânicas, como o caso da Vila de Encantadas. Para A. C. DIEGUES (1998, p. 53), devem ser salientadas as riquezas do imaginário, como culturas e misticismo, crenças e hábitos relacionados às comunidades insulares. Para esses habitantes "o mar não se constitui meramente num espaço físico, mas o lugar de seu trabalho, de sua sobrevivência e sobre o qual dispõem de grande conhecimento acumulado" (DIEGUES, 1998, p. 53).

Além do teatro, existe a pesca artesanal, festas religiosas, o futebol na praia (Foto 7), a pesca da Tainha, a mariscada, o lambe-lambe (prato tradicional) e o bastante apreciado pelos habitantes e turistas, forró. Estas manifestações constituíam, de acordo com os depoimentos, as principais manifestações culturais ocorrentes.

As informações obtidas sobre as questões da atividade turística foram variadas, pela razão de ser um tema bastante amplo. Em aspectos gerais foi possível considerar alguns pontos que marcaram um discurso coletivo, os quais estão a seguir colocados.

A atividade turística era responsável pelas principais atividades econômicas. Serviços diretos e indiretos, formais e informais ocorrem oportunizando emprego para os trabalhadores locais. Existiu certa crítica por parte dos entrevistados, de o fato de os comerciantes e/ou empresários - externos - utilizar mão de obra de pessoas de fora para trabalharem em seus estabelecimentos. Isso representou, na verdade, uma reclamação por parte da comunidade. A justificativa de isto ocorrer estava no argumento de que o habitante tradicional não possuia preparo adequado para serviços de uma maneira geral. 


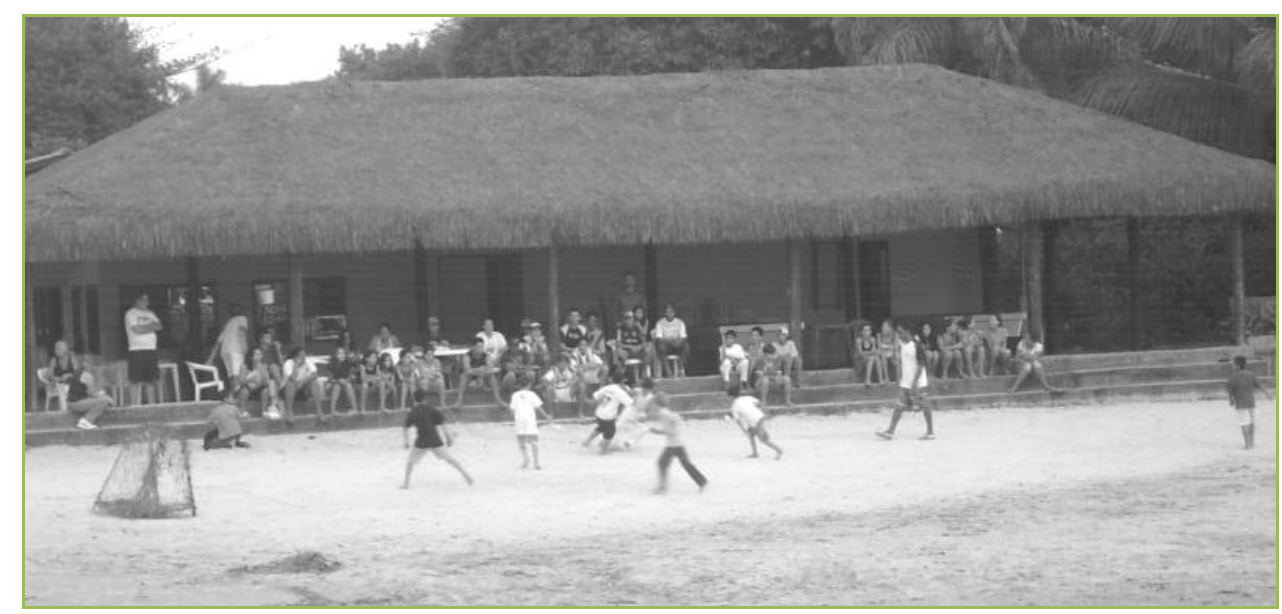

FOTO 6 - CRIANÇAS JOGANDO FUTEBOL NA AREIA

FOTO: PAULO J. SOAVINSKY (2003)

O turismo na ilha vinha apresentando mudanças qualitativas, no que diz respeito ao padrão de serviços oferecidos. Isto se estabeleceu entre outras razões, pela mudança de perfil do turista no local. A taxa de visitação foi um aspecto que, à época, vinha acarretando neste aspecto. A cobrança da taxa era considerada positiva pela maioria dos entrevistados. A maior parte da dos entrevistados considerou que a Ilha do Mel deveria estabelecer o turismo de qualidade.

Dentre os aspectos negativos, estava a gestão do turismo no local. Por ser considerado um turismo espontâneo, sem planejamento prévio, existiam aspectos de ilegalidade e informalidade bastante representativos. Desta maneira não existia um mecanismo de acompanhamento ou avaliação sobre gastos, nem tampouco estratégias de competitividade entre as empresas. Minoria dos empreendimentos estava cadastrada no Ministério do Turismo, de acordo com informação relevante. Este controle, ou acompanhamento deveria existir a partir da aproximação entre instituições públicas estaduais.

Com relação ao ecoturismo, o discurso coletivo afirmou ser um dos atrativos da Ilha do Mel como um todo. O principal deles. Alguns discursos colocaram que ocorre no local uma mistura de ecoturismo com turismo de massa.

A análise permite afirmar que existia um desejo pelo ecoturismo, mas que este conceito não estava bem esclarecido quanto aos seus princípios e significados para a maior parte dos entrevistados. Esta questão da indefinição do entendimento sobre o 
ecoturismo pode ser percebida na sociedade local, possivelmente pelautilização errônea do conceito, dada sua vulgarização (FERRETTI, 2002).

De acordo com os depoimentos sobre a pesca no local, tratava-se de uma atividade tradicional da comunidade, que ao longo dos anos passou a sofrer depreciação. Os pescadores não tiveram estímulos por parte do governo como cooperativas ou qualquer outra oportunidade para desenvolverem a pesca de maneira rentável e equilibrada. Tornou-se, para os entrevistados mais representativos neste quesito, inviável para o pescador viver da pesca, ocorrendo mudança de ocupação da classe, para atividades ligadas ao turismo.

Esta questão da mudança de atividades, devido à evolução dos padrões de consumo e produção, corresponde ao que Bernardes (1998) coloca como renovação técnica. Este fenômeno marca a manifestação do processo de modernização, ocorrendo nas chamadas "organizações sociais em desequilíbrio", como reflexos de uma tendência global.

Alguns entrevistados alegaram que, à época, não havia recursos pesqueiros em abundância como no passado (Fotos 7 e 8), que garantissem a pesca como uma atividade econômica promissora. Ocorriam casos pontuais, de pescadores que sofriam com as variações que a atividade representa. O grau de tecnificação da pesca é de baixa escala, semelhante à pesca artesanal. Uma discrepância nas informações negou a existência da pesca artesanal no local, afirmando ser atividade comercial concentrada nas mãos de poucos.
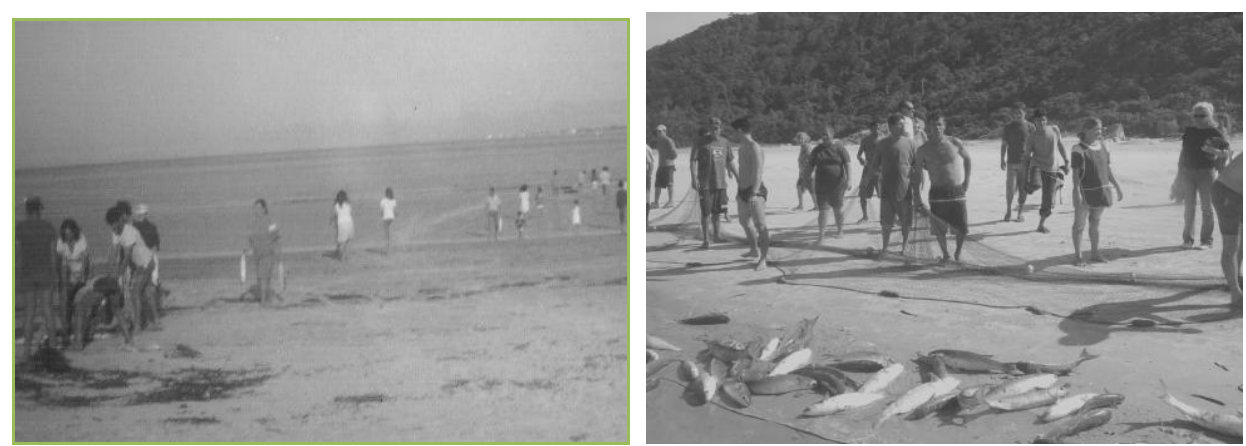

FOTOS 7 E 8 - HOMENS E MULHERES PARTICIPANDO DA PESCA DA TAINHA NA DÉCADA DE 1970 E NOS DIAS ATUAIS

FOTOS: PAULO J. SOAVINSKY (MEADOS DA DÉCADA DE 1970) E (2007).

$\mathrm{O}$ artesanato original da Ilha do Mel tinha em raros habitantes, prática e significância enquanto atividade econômica para a população local. Um discurso 
individual alegou falta de vontade por parte dos habitantes em promover o artesanato tradicional como ocorria em Paranaguá. Considerando a maioria das entrevistas concedidas sobre o assunto, esta atividade ocorria de maneira comercial, por vendedores ambulantes de produtos oriundos de outras regiões ou localidades.

A mudança de padrões de produção e consumo regido por tendências econômicas segue a mesma teoria colocada no item anterior, relativo à questão da pesca. A questão da Renovação técnica.

\section{CONCLUSÃO}

A Vila de Encantadas é uma localidade onde existem relações sociais fortemente marcadas pela influência cultural de novos atores sociais, fato esse que teve influência mais destacada com o crescimento da exploração turística. A partir de meados da década de 1980, o turismo manifestou seus impactos mais representativos no local. Considerando-se a modificação da paisagem e dos recursos, tal fato estabeleceu a vocação desta localidade para atividades econômicas ligadas ao turismo. Este processo, entretanto ocorreu sem atuação de fatores balizadores no que diz respeito à gestão do território. Os atores sociais transformaram o espaço de acordo com suas próprias vontades, sobretudo os responsáveis pelos empreendimentos comerciais. Isto ocasionou impactos na paisagem do setor de ocupação, nas áreas protegidas de entorno e na cultura do local.

Entre 2006 e janeiro de 2007 foi possível constatar que a Ilha do Mel, em especial a Vila de Encantadas, passava por uma crise social. Este fato resultava de como o período compreendido entre a metade final da década de 1980 até então se mostrou como o processo de turistificação desta ilha, tendo deixado impactos profundos nos modos de vida e manifestações culturais.

É impossível não atribuir a esses aproximados vinte anos a deficitária política de gestão e manejo em vigor. Os órgãos públicos tiveram na inação grande parcela de responsabilidade pelos impactos territoriais ocorridos na ilha. O turismo implantado da maneira desfavorável ao próprio turismo. A visão setorial das instituições públicas que estiveram à frente dos processos decisórios mais importantes acabou por comprometer tal quadro. 
O estudo permitiu compreender mais sobre o posicionamento da sociedade deste local e quais os aspectos envolvidos na complexidade dos problemas existentes frente às condições sociais verificadas. Entendido como o auge de um quadro de insatisfação da sociedade para com a realidade, tal contexto passou a ser trabalhado nas reivindicações e atitudes da população para a reversão daquele quadro. O importante que se notou é da manutenção de hábitos, ligados ou não ao turismo, no cotidiano. Associando esta notação à fase do turismo anteriormente mencionada, é possível atribuir à população da época desta pesquisa, a sensação de crise que precede tomada de decisões estratégicas.

Algumas manifestações culturais de gerações antecessoras praticamente sumiram, no período de cerca de duas décadas. A rusticidade e o modo de vida de antes não predomina mais nas famílias e na comunidade, e as atividades econômicas voltadas ao atendimento do turismo passa a determinar o modo de vida da população local. Boa parte dos habitantes tradicionais teve que atuar em tarefas menos rentáveis da economia ligada aos serviços turísticos, como opção economicamente viável. Os habitantes passaram a perder sua auto-estima, proporcionalmente ao passo que migrantes externos instalaram-se e modificaram a paisagem de antes. O impacto da miscigenação cultural, entre outros fatores a reconhecer a necessidade de conhecimentos e mecanismos de reversão deste quadro.

O caso da Vila de Encantadas constitui-se em campo de disputa envolvendo diferentes grupos sociais, dentre sociedade civil, poder público e poder privado. Estas constatações permitem levantar a hipótese desta localidade se configurar em um território a parte dentre as diferentes zonas de toda a Ilha, marcado por características, potencialidades, problemáticas e vocações específicas. Fato esse que, após o período abrangido por este estudo pôde ser levado em consideração para movimentos sociais de reação, em especial no quesito cultural, a ser explorado por novos estudos.

\section{REFERÊNCIAS}

ALEGRIA, M. F.; SILVA, H. P. Refletindo sobre a dimensão coletivista do Conselho Gestor. In: Anais do II Seminário de Áreas Protegidas e Inclusão Social. Programa EICOS-IP/UFRJ, 2006. 
AZEVEDO, J. Turismo, cultura, patrimônio In: Coriolano, L.N.M.C. (Org.). Turismo com ética. Fortaleza: UECE, 1998.

BERNARDES, J. A. Mudança Técnica e Espaço: Uma Proposta de Investigação. In: Castro, I. E.; Gomes, P. C. C.; Corrêa R. L. (Orgs.) Geografia: Conceitos e Temas. Rio de Janeiro: Bertrand Brasil, 1998.

BRASIL. Lei 9985, de 18 de Julho de 2000. Disponível em: <http://www.lei.adv.br/9985-00.htm>. Acesso em: 13/10/2009.

CARDOSO, F. H. C.; FALETTO, E. Dependência e Subdesenvolvimento na América Latina - ensaio de interpretação sociológica. 6. ed. Rio de Janeiro: Zahar, 1981.

DIAS, R. Turismo Sustentável e Meio Ambiente. São Paulo: Atlas, 2003.

DIEGUES, A. C. Ilhas e Mares - simbólico e imaginário. São Paulo: Hucitec, 1998.

ESTEVES, C. J. O. Turismo e qualidade da água na Ilha do Mel (Litoral do Paraná). 173fls. Dissertação (Mestrado em Geografia). Universidade Federal do Paraná, Curitiba. 2004.

FERRETTI, E. R. Turismo e Meio Ambiente: uma abordagem integrada. São Paulo: Roca, 2002.

FIGUEIREDO, J. C. Contribuição para a Geografia da Ilha do Mel. Curitiba, 1954. FURTADO, C. O Subdesenvolvimento Revisitado In: Revista Economia e Sociedade, v. 1. Campinas: 1992 - Ago. (pp.5-19).

KNAFOU, R. Turismo e Território: por uma abordagem científica do turismo. In: Rodrigues, A. (Org.) Turismo e Geografia: referenciais teóricos e enfoques regionais. São Paulo: Hucitec, 1999.

KRAEMER, M. C. Malhas da Pobreza: exploração do trabalho de pescadores artesanais na Baía de Paranaguá. 185fls. Dissertação (Mestrado em Ciências Sociais), Antropologia, Pontifícia Universidade Católica de São Paulo, São Paulo. 1978.

KRIPPENDORF, J. Sociologia do Turismo: para uma nova compreensão do lazer e das viagens. São Paulo: Aleph, 2000.

LAVILLE, C.; DIONNE. J. A construção do saber: manual de metodologia da pesquisa em ciências humanas. Belo Horizonte: Ed. UFMG: 1999.

MARTINS, R. História do Paraná. Curitiba: Travessa dos Editores, 1995.

MENEZES, J. N. C. História \& Turismo Cultural. Belo Horizonte, Autêntica: 2004.

MICHAELIS Moderno Dicionário da Língua Portuguesa. São Paulo: Cia. Melhoramentos, 1998. 
PARANÁ. Lei Estadual $\mathbf{n}^{\mathbf{0}} \mathbf{1 . 2 1 1} / \mathbf{1 9 5 3}$ de 16 de setembro de 1953. Dispõe sobre o patrimônio histórico, artístico e natural do Estado do Paraná. da Fazenda.

Portaria $\mathbf{n}^{\mathbf{0}}$ 160/1982 de 15 de abril de 1982 da Secretaria Geral do Ministério

Coletânea da Legislação e Documentação sobre a Ilha do Mel. Instituto Ambiental do Paraná, 1986

Plano de Manejo - Estação Ecológica da Ilha do Mel - PR. Instituto Ambiental do Paraná e Secretaria do Estado de Meio Ambiente e Recursos Hídricos: 1996.

Ilha do Mel - Análise da expansão urbana. Comissão para elaboração do plano de instruções básicas. Curitiba, 1999.

Instituto Ambiental do Paraná. Portaria IAP, de 19 de Maio de 2005.

QUEIROZ-TELLES, D. H.; GONÇALVES-GANDARA, J. M. Aspectos de infraestrutura e serviços como indicadores da turistificação na Vila de Encantadas, Ilha do Mel (Brasil). El Periplo Sustentable. Universidad Autónoma del Estado de México. N.21 Julio / Diciembre 2011.

RODRIGUES, A. B. Turismo e Geografia. Reflexões teóricas e enfoques regionais. São Paulo: Hucitec, 1995.

RUSCHMANN, D. Turismo e Ambiente: reflexões e propostas. São Paulo: Hucitec, 1997.

SANTOS, M. Espaço e método 3. ed. São Paulo: Nobel, 1992.

Da totalidade ao Lugar São Paulo: Edusp, 2008.

SILVEIRA, M. A. Ecoturismo na Ilha do Mel/Paraná. In: Turismo e Meio Ambiente, v. 1. Fortaleza: Ed. UECE, 1998.

SOARES, A. Informação verbal. Atividades do Operação Verão/IAP. Dez. 2006.

SOUZA, M. L.O território: sobre espaço e poder, autonomia e desenvolvimento. Em: Castro, I. E.; Gomes, P. C. C.; Corrêa R. L. (Org.) Geografia: conceitos e temas. Rio de Janeiro: Bertrand Brasil, 1995.

STADEN, H. Duas viagens ao Brasil: primeiros registros sobre o Brasil. Tradução de Angel Bojadsen. Porto Alegre, RS: L\&PM, 2009.

STRAUSS, C. L. Antropologia estrutural 5. ed. Rio de Janeiro: Tempo Brasileiro, 1996. 
TELLES, D. H. Q. Análise sobre os aspectos socioambientais e da atividade turística na Vila de Encantadas - Ilha do Mel. 106 f. Dissertação (Mestrado em Geografia). Programa de Mestrado em Geografia da Universidade Federal do Paraná, 2007.

TELLES, D. H. Q.; GÂNDARA, J. M. G. Desenvolvimento do Turismo e Questões Socioambientais na Vila de Encantadas, Ilha do Mel-PR: uma análise a partir da perspectiva da sociedade local In: Revista Turismo Visão e Ação, V. 11. n. 1. 2009.

TELlES, D. H. Q.; GÂNDARA, J. M. G.; FONTOURA, L.; SPERB, M. Gestión Territorial y Planificación Participativa en la Ilha do Mel - Brasil: Conceptos y Prácticas. Estudios y Perspectivas en Turismo. V. 20. 2011.

TOURAINE, A. Crítica da modernidade. Petrópolis: Vozes, 2002.

VERA, J. F.; LÓPEZ PALOMEQUE, F.; MARCHENA, M. J.; ANTÓN, S. Análisis territorial del turismo. Barcelona: Ariel Geográfica, 1997.

YÁZIGI, E. A alma do lugar - Turismo, planejamento e cotidiano em litorais e montanhas. São Paulo: Contexto, 2001.

Turismo, uma esperança condicional. São Paulo: Global Universitária, 2003.

A. A definição do conceito de Patrimônio Ambiental Urbano em países emergentes In: GeoLNova. Revista de Geografia da Universidade Nova de Lisboa. N.12. Portugal, 2006.

Recebido em: 29-08-2011.

Aprovado em: 29-09-2011. 